\title{
Effects of level of social contact on dairy calf behavior and health
}

\author{
Margit Bak Jensen*1 and Lars Erik Larsen† \\ *Department of Animal Science, Aarhus University, Blichers Allé 20, DK-8830 Tjele, Denmark \\ †National Veterinary Institute, Technical University of Denmark, Bülowsvej 27, DK-1870 Frederiksberg C, Denmark
}

\section{ABSTRACT}

Housing preweaned dairy calves in pairs rather than individually has been found to positively affect behavioral responses in novel social and environmental situations, but concerns have been raised that close contact among very young animals may impair their health. In previous studies, the level of social contact permitted in individual housing has been auditory, visual, or physical contact. It is unclear how these various levels of social contact compare with each other and to pair housing, when their effects on behavior and health are considered, and whether the timing of pair housing has an effect. To investigate this, 110 Holstein calves (50 males, 60 females) in 11 blocks were paired according to birth date. Within $60 \mathrm{~h}$ of birth, each pair of calves was allocated to 1 of 5 treatments: individual housing with auditory contact (I), individual housing with auditory and visual contact $(\mathrm{V})$, individual housing with auditory, visual, and tactile contact $(\mathrm{T})$, pair housing $(\mathrm{P})$, or individual housing with auditory and visual contact the first $2 \mathrm{wk}$ followed by pair housing (VP). At $6 \mathrm{wk}$ of age, calves were subjected to a social test and a novel environment test. In the social test, all pair-housed calves ( $\mathrm{P}$ and VP) had a shorter latency to sniff an unfamiliar calf than did individually housed calves (I, $\mathrm{V}$, and $\mathrm{T}$ ), whereas calves with physical contact ( $\mathrm{T}$, $\mathrm{P}$, and VP) sniffed the unfamiliar calf for longer than calves on the remaining treatments (I and V). In the novel environment test, calves with physical contact ( $\mathrm{T}, \mathrm{P}$, and VP) had a lower heart rate, and more of these calves vocalized during the test compared with calves without physical contact (I and V). No effect of treatment was found for clinical scores, levels of the 5 most common pathogens in feces, or in development of serum antibodies against the 3 most common respiratory pathogens. Calves housed individually are more fearful of unfamiliar calves than are pair-housed calves. Contrary to common belief, the allowance of physical

Received July 29, 2013.

Accepted April 6, 2014.

${ }^{1}$ Corresponding author: MargitBak.Jensen@agrsci.dk contact and pair housing had no effects on the health of the calves.

Key words: behavior, health, social, animal welfare

\section{INTRODUCTION}

Providing social contact to preweaned dairy calves by housing them in pairs or small groups rather than individually positively affects their behavior. Pair-housed calves approach and sniff another calf more readily than individually housed calves, whereas individually housed calves forcefully push other calves once social interaction is initiated (Duve and Jensen, 2011; De Paula Vieira et al., 2012). This indicates less ability to regulate social interactions among individually housed calves and is likely due to limited social experience. In novel environments, individually housed calves respond more fearfully, involving an elevated heart rate (Jensen et al., 1997). Furthermore, the inability to perform social behaviors may be the cause of abnormal behavior such as excessive licking of their own bodies and fixtures seen in individually housed calves (Bokkers and Koene, 2001). Finally, social housing of preweaned calves has resulted in higher intakes of concentrate (De Paula Vieira et al., 2010) and hay (Hepola et al., 2006) compared with calves in individual housing. However, individual housing may vary in regard to the level of social contact possible. In some types of individual housing, tactile contact between neighboring calves is possible, whereas in others, calves can see but not touch each other. In some cases, when calves are housed in closed individual pens or hutches with no calves placed opposite, they merely have auditory contact with conspecifics. The first aim of the study was to investigate the effect of level of social contact on calf behavior. We hypothesize that a higher level of social contact would result in a lower fear response to novel environments and unfamiliar calves, a lower level of abnormal behavior in the home environment, and a higher intake of concentrate. Under semi-natural conditions, calves stayed in the proximity of their dams for the first weeks of life (Lidfors and Jensen, 1988), whereas under production conditions, stronger bonds were formed among calves that were paired at birth rather than later (Duve 
and Jensen 2011). Therefore, an additional social treatment, where calves were pair-housed from the age of $2 \mathrm{wk}$, was included to investigate whether postponing pair housing until this age affected the aforementioned behavioral responses.

Normal development of behavior is one concern for animal welfare, and animal health is another. It may make sense to limit the level of social contact among calves to limit direct horizontal transmission of pathogens. In support of this, Gulliksen et al. (2009) found a higher mortality for calves housed in groups before the age of 1 mo compared with individually housed calves; moreover, calves that had been individually housed preweaning had a lower risk of respiratory disease after weaning compared with calves that had been housed in groups (Svensson et al., 2006). On the other hand, Svensson et al. (2003) showed that preweaned calves housed in small groups had a lower incidence of respiratory disease than calves housed in large groups or in individual pens, suggesting that the adverse effects of group housing on health is a question of group size rather than of social contact per se. Few studies have compared health among calves with varying levels of contact in individual pens or in pair housing, and thus evidence is scarce as regards the health effects of avoiding tactile contact between calves. The second aim of the present study was to investigate the effect of the level and timing of social contact on calf health.

\section{MATERIALS AND METHODS}

The study was conducted at the Aarhus University research facilities (Foulum, Denmark). Calves were housed and managed according to a protocol approved by the Danish Animal Experiments Inspectorate, Ministry of Justice, Copenhagen, Denmark (reference number 2010/561-1780).

\section{Animals, Feeding, and Management}

One hundred ten Danish Holstein dairy calves (50 male and 60 female) in 11 blocks were paired according to birth date. All calves were born in individual calving pens and separated from their dams between 2 and 6 $\mathrm{h}$ after birth. If the youngest calf of a pair was born within $6 \mathrm{~h}$ of the oldest calf of the pair, then the 2 calves were moved directly from their calving pen to the experimental pens placed in an adjacent building. If the youngest calf of a pair was not born within $6 \mathrm{~h}$ of the birth of the oldest, then the oldest calf was placed in a clean straw-bedded individual calf pen placed in a room adjacent to the calving facility until the youngest calf was born, accepting an age difference within a pair of maximum $60 \mathrm{~h}$. The 2 calves were moved together to the experimental building within 2 to $6 \mathrm{~h}$ of the birth of the youngest calf. The birth weight of the calves was $43 \pm 5.9 \mathrm{~kg}$ (mean $\pm \mathrm{SD})$.

Calves were fed milk twice daily at 0600 and 1600 $\mathrm{h}$, and the calves were always fed in the same order. Calves were offered $4 \mathrm{~L}$ of colostrum within $6 \mathrm{~h}$ of birth. Until the youngest calf of a pair was $4 \mathrm{~d}$ old, both calves of a pair were offered $6 \mathrm{~L}$ of colostrum per day given in 2 daily feedings of $3 \mathrm{~L}$. The colostrum was preferably from the dam, but was supplemented from a colostrum pool if the dam's quality did not meet minimum standards $(\geq 50 \mathrm{mg}$ of $\mathrm{IgG} / \mathrm{mL})$. From d 4 until the end of the experimental period, calves were fed $6 \mathrm{~L}$ of whole milk per day in 2 daily feedings of $3 \mathrm{~L}$. All milk feedings were offered in teat buckets (plastic buckets fitted with one teat; Peach Teat, Skellerup Industries Ltd., Christchurch, New Zealand). All buckets were individually marked and cleaned between feedings, and each calf was always offered milk from the same bucket. Concentrates (18\% CP, $4 \%$ fat, and 6\% fiber; Grøn Kalv Valset; DLG, Copenhagen, Denmark), hay, and water were offered ad libitum throughout the study.

\section{Experimental Treatments and Design}

Within each block, pairs of calves were allocated in a random order to 1 of 5 treatments: individual housing with auditory contact (I), individual housing with auditory and visual contact ( $\mathbf{V})$, individual housing with auditory, visual, and tactile contact ( $\mathbf{T})$, pair housing $(\mathbf{P})$, or auditory and visual contact the first $2 \mathrm{wk}$ followed by pair housing (VP). Pair housing at 2 wk of age (VP) was included to investigate if pair housing within $3 \mathrm{~d}$ of birth $(\mathrm{P})$ differed from pair housing at 2 wk of age.

All pens had sides made from vertical tubular metal bars (bar diameter: $2.5 \mathrm{~cm}$; distance between bars: 10 $\mathrm{cm})$. Pens of calves of different treatments were positioned $1.5 \mathrm{~m}$ apart, ensuring that calves did not have physical contact with calves on other treatments. Thus, pair-housed calves (P) had full social contact with only their pair partner but had visual contact with other calves in the building. Calves housed individually with visual and tactile contact $(\mathrm{T})$ were housed in adjacent pens and could have physical contact with their pair partner through the bars of the separating pen side and visual contact with other calves in the building. Calves housed individually with visual contact (V) were housed in adjacent pens positioned $1.5 \mathrm{~m}$ apart, allowing visual contact with the pair partner as well as other calves in the building. However, the sides of isolation pens (I) were covered with plywood, which also covered the feeding area, and thus prevented all social contact with other calves except auditory contact with 
the calves in the building. Calves housed in individual housing with visual contact for the first $2 \mathrm{wk}$ followed by pair housing (VP) were housed in adjacent pens positioned $1.5 \mathrm{~m}$ apart for the first $2 \mathrm{wk}$, after which 1 of the 2 pens was enlarged to the size of a pair pen as described above; the 2 calves were housed in this pen for the remaining of the treatment period.

Pens within a block were positioned in the same area of the building, and the position of treatment within the block was randomized. All individual and pair pens were straw-bedded. Pair pens measured $1.5 \times 3.0 \mathrm{~m}$, whereas individual pens measured $1.5 \times 1.5 \mathrm{~m}$; that is, space allowance was $2.25 \mathrm{~m}^{2}$ for all calves. Each block included 5 calf pairs, 1 pair of each treatment, and the blocks were created as calves were born. The maximum age difference between the youngest and the oldest calf within a block was $10(5-15) \mathrm{d}$ (median, with range in parentheses).

Calves were housed in the experimental pens until the youngest calf of a block was $50 \mathrm{~d}$ old, at which stage they were moved to group pens just after morning milk feeding.

\section{Behavioral Observations}

Undisturbed Behavior. Calves' undisturbed behavior was recorded via video cameras positioned above each experimental pen (TVCCD-140IR, Monacor, Bremen, Germany). Behavior was recorded over $24 \mathrm{~h}$ starting at midnight when the youngest calf of a block was $21 \mathrm{~d}$ old. From these recordings, the postures upright (body supported by legs, calf may be standing or walking) and lying (lying on sternum or side, head may be rested or raised) were recorded by one observer along with the behaviors feeding (calf's head is in feeding trough or over feeding trough while the calf is chewing), sniffing or licking fixtures (calf's muzzle is in contact with, or in close proximity of, any fixtures of the pen), licking own body (calf's tongue is in contact with own skin or fur), and sniffing or licking peer (calf's muzzle or tongue is in contact with, or close to, the head, neck, or body of another calf). Instantaneous recording (Martin and Bateson, 2007) at 5-min intervals was used.

Behavioral Tests. All calves were individually subjected to a social test when the youngest calf in a block was $44 \mathrm{~d}$ old and a novel environment test when the youngest calf in a block was $46 \mathrm{~d}$ old.

The social test was conducted in an elongated room $(2.5 \times 11.2 \mathrm{~m})$ with concrete floor and solid walls. A start box was situated at one end of the room and an unfamiliar stimulus calf was tethered at the opposite end of the room via a halter and a $1.5-\mathrm{m}$ rope tied to a ring in the floor, positioned $1.6 \mathrm{~m}$ from the end wall. Lines were marked on the floor every $2 \mathrm{~m}$, except in the area with the stimulus calf, where a line was drawn $3.2 \mathrm{~m}$ from the end wall. The stimulus calf could move about in the $3.2 \times 2.5 \mathrm{~m}$ area. The start box, measuring $1.9 \times 0.9 \mathrm{~m}$, was made from vertical tubular metal bars, and the stimulus calf was visible to the test calf from the start box. Two stimulus calves were used per block; each stimulus calf was used to test one calf from each treatment. All stimulus calves had previously been housed in individual pens with tactile contact to one other calf and were of similar age and weight as the test calves. The test was initiated by placing the test calf in the start box; after 1 min, the door to the arena was opened. Calves that did not leave the start box during the first minute after opening were pushed gently out of the start box into the arena, and the social test lasted 10 min after the calf had entered the arena. Video recordings were conducted via the camera (TVCCD-460, Monacor) placed above the arena, and the video image was displayed on a monitor placed in an adjacent room. Time from entering the arena until sniffing the stimulus calf (the time from the calf entered the arena until its muzzle touches the stimulus calf for the first time) and number of lines crossed (a line was crossed once both forelegs had crossed the line) were recorded directly via the monitor by one observer who was blinded to treatments. From the video recordings, the following behaviors of the experimental calf were recorded: sniffing or licking the stimulus calf's muzzle (calf's muzzle or tongue is in contact with muzzle of stimulus calf), sniffing or licking the stimulus calf's head or body (calf's muzzle or tongue is in contact with the head, except muzzle, or body of stimulus calf), and sniffing the wall or floor of the arena (calf's muzzle is in contact with, or close to, the wall or the floor of the arena). All behaviors from video were recorded by one observer who was blind to treatment. Continuous recording (Martin and Bateson, 2007) throughout the 10 min of the test was applied.

The novel environment test was conducted in an equilateral $(5.5 \mathrm{~m})$ triangular arena with 1.6-m-high walls made of plywood. On the concrete floor, 9 equally sized areas were marked; the central third of the triangle was divided into three $1.44-\mathrm{m}^{2}$ triangles, whereas the peripheral two-thirds was divided into six $1.44-\mathrm{m}^{2}$ right-angled trapezoids (Figure 1). The start box measured $1.9 \times 0.9 \mathrm{~m}$ and had 1.6-m-high plywood sides. The gate to the arena from the start box was made of vertical tubular metal bars and could be operated from outside the arena via a steel wire. The test calf was placed in the start box and the door to the arena was opened after $1 \mathrm{~min}$. Calves that did not leave the start box during the first minute after opening were pushed gently out of the start box into the arena, and the duration of the test was $10 \mathrm{~min}$ from the time the calf had 
entered the arena. Vocalizations were recorded directly by one observer who was blinded to treatment. The number of areas entered during the 10-min duration of the test (an area was entered once both forelegs were placed in the area) was also recorded directly by the same observer via a monitor connected to the camera placed above the arena.

During both the social test and the novel environment test, the heart rate of each animal was recorded using a Polar Vantage heart rate monitor (Polar Electro Oy, Kempele, Finland), consisting of an electrode belt with a built-in transmitter and a wristwatch receiver. One of 2 electrodes was placed on the left side of the calf, just behind the elbow, and the other was placed behind the right scapula. Before application, the electrodes were moistened with water and an electro-conductive gel was applied. The monitor was set to record continuously, and the mean heart rate during the 10-min test was calculated and used as input in the analysis.

\section{Intake, Gain, and Health Measurements}

Concentrate Intake and BW Gain. Concentrate intake was measured at the pen level $4 \mathrm{~d} / \mathrm{wk}$ for $4 \mathrm{wk}$, when the youngest calf in a block was 21 to $49 \mathrm{~d}$ old. Calves were weighed at birth when being moved to the experimental building, at the age of $28 \mathrm{~d}$, and at the end of the experiment when the youngest calf in the block was $49 \mathrm{~d}$ old.

Clinical Scoring and Fecal Samples. Clinical scorings focused on the most prevalent disease syndrome in Danish calves (enteric and respiratory diseases) and were conducted by 1 trained technician on a fixed day of the week when the calf was $1,2,3,4$, and 6 wk old and included the following: (a) Feces score after stimulation to defecate $(0=$ firm, $1=$ mush-like, $2=$ gruel-like, or $3=$ watery $)$; (b) breathing $(0=$ unhindered, $1=$ difficult, or $2=$ very difficult); (c) nasal discharge $(0=$ absence, $1=$ presence $) ;(d)$ coughing $(0$ $=$ absence, $1=$ presence $)$; and (e) navel infection $(0=$ absence, $1=$ presence). We observed no cases of navel infection. Because we observed no cases of very difficult breathing, breathing score was a binary variable (unhindered or difficult). A novel score ("respiratory score') was constructed from the combined scores for breathing, nasal discharge, and coughing. The respiratory score was set to 1 if at least one of following was scored: difficult breathing, presence of nasal discharge, or presence of coughing; otherwise, it was set to zero. There were few observations of fecal scores 2 and 3; therefore, fecal score was converted into a binary variable: fecal consistency was set to zero if original scores were equal to zero and to 1 if original scores were above zero (scores 1, 2, and 3).

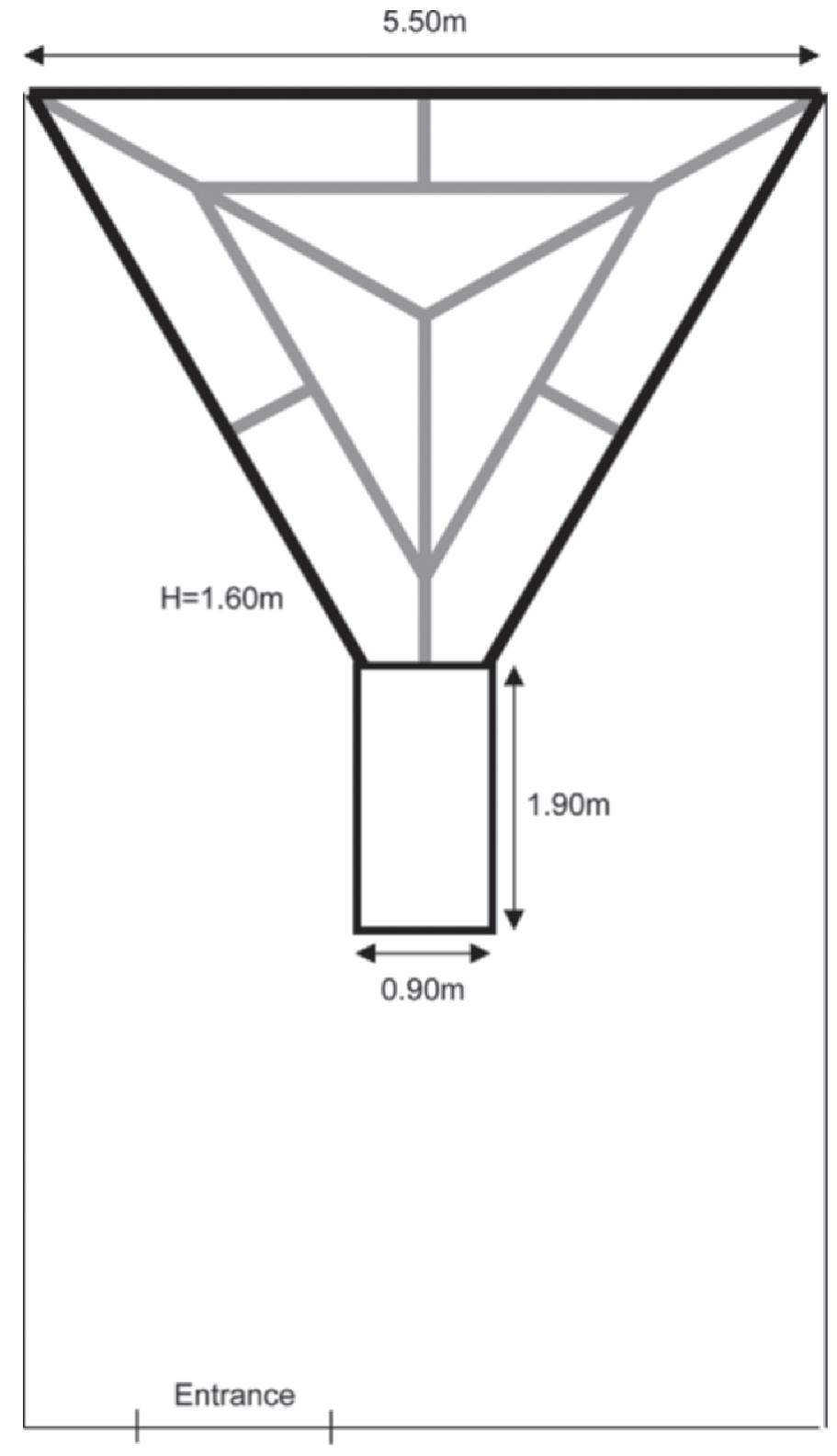

\section{Calf barn}

Figure 1. The equilateral triangular arena used for the novel environment test. The arena was placed in a room adjacent to the calf barn. On the arena floor, 9 areas of equal size were marked. The rectangular start pen opening into the arena could be operated from outside the arena. $\mathrm{H}=$ height.

During the health checks, fecal samples (10 to 20 g) were obtained using a rubber glove from each calf by digital exploration or by collection of fresh stool. Samples were kept in $155-\mathrm{mL}$ plastic containers with lids and were refrigerated shortly after collection and stored refrigerated until they were examined for the most common enzootic pathogens in Danish calves. Tests for bovine rotavirus (BRV) and bovine corona- 
virus (BCV) were performed by a semiquantitative double-sandwich ELISA method (Grauballe et al., 1981). Culturing and serotyping of Escherichia coli was performed as previously described (de Graaf et al., 1980). Parasite eggs and oocysts were quantified using a modified McMaster method (Henriksen and Aagaard 1976). Shedding of Cryptosporidium parvum oocysts was analyzed by a modified Ziehl-Neelsen technique (Henriksen and Pohlenz, 1981).

Blood Samples. Blood samples (plain, unstabilized) were drawn from the jugular vein by venipuncture at approximately $0800 \mathrm{~h}$ when the calf was $4 \mathrm{~d}$ old and again when the youngest calf of the block was $49 \mathrm{~d}$ old. Both samples were analyzed for antibodies against BCV, parainfluenza-3 virus (PI-3), and bovine respiratory syncytial virus (BRSV) using commercial ELISA kits (Svanova, Uppsala, Sweden). The results were expressed as percentage inhibition, as follows: [optical density (OD) of negative control - OD of sample]/OD of negative control $\times 100$. To determine the level of the maternally derived immunity, the concentration of total bovine $\operatorname{IgG}$ in the first serum sample taken from each calf on d 4 was determined by a competitive immunoassay (ELISA; P. M. H. Heegaard, Technical University of Denmark, Frederiksberg, Denmark; personal communication). The serum IgG concentration averaged $23.6 \mathrm{~g} / \mathrm{L}$ and ranged from 6.3 to $39.5 \mathrm{~g} / \mathrm{L}$. Only one calf had serum IgG concentration $<10 \mathrm{~g} / \mathrm{L}$.

\section{Statistical Analyses}

Undisturbed Behavior. Data for undisturbed behavior in the home pen were analyzed using PROC MIXED (SAS Institute Inc., Cary, NC). The initial model included the fixed effects of social contact treatment (I, V, T, P, VP) and calf sex (male, female), and the interaction between social contact and sex. Block and pair were included as random effects. In the initial analyses, contrasts were calculated between treatments $\mathrm{P}$ and VP to test for effect of age at pair housing. If no effect $(P>0.10)$ was found, the data for treatments $\mathrm{P}$ and VP were pooled (and termed treatment $\mathbf{A P}$ ); in a subsequent analysis, the 4 treatments (I, V, T, AP) were compared using contrasts. Undisturbed behavior included the duration of upright, feeding, sniffing or licking fixtures, licking own body, and sniffing or licking peer. The duration of feeding was transformed by the square root before analysis to meet the assumptions of normal distribution, which were checked by visual inspection of the residuals. A subset of the data including treatments $\mathrm{T}, \mathrm{P}$, and $\mathrm{VP}$ was used to analyze the effect of treatment on the duration of sniffing and licking the peer. An analysis similar to that described above was used except it only included calves on these
3 treatments. Additionally, treatments $\mathrm{P}$ and VP were pooled as treatment AP in a subsequent analysis if no differences between these 2 treatments were found.

Behavioral Tests. The number of areas entered in the novel environment test was square root-transformed and analyzed in 2 steps as described above for undisturbed behavior. Continuous variables from the social test were analyzed as described above for undisturbed behavior, except that the identity of the stimulus calf was included as an additional random effect. These variables (duration of sniffing or licking the stimulus calf's muzzle, sniffing or licking the stimulus calf's head or body, sniffing the wall or floor, the latency to sniff the stimulus calf, and the number of lines crossed) were all transformed by the square root to meet the assumptions of normal distribution. For latency to sniff the stimulus calf, whether the calf was pushed into the arena or not $(1,0)$ was included in the model. The mean heart rate during the social test and the novel environment test was analyzed as described above, except the number of lines crossed or number of areas entered, respectively, was included as a covariate. An initial model for mean heart rate included whether the calf had been pushed into the arena or not $(1,0)$, but this was not significant for either of the 2 tests and was subsequently excluded from the model.

Finally, the effect of treatment (I, V, T, P, VP) on whether the calf was pushed into the arena or not in the social test was analyzed by $\chi^{2}$ test. For the novel environment test, whether the calf had been defecating or not and the number of calves vocalizing during the test were also analyzed for treatment effect by the $\chi^{2}$ test.

$\boldsymbol{B} \boldsymbol{W}$ Gain. Average daily BW gain was calculated for each individual calf in the period from birth to $28 \mathrm{~d}$ of age and analyzed as described above for undisturbed behavior, except that birth weight was included as a covariate. Body weight at the end of the experimental period (when the youngest calf in the block was $49 \mathrm{~d}$ old) was analyzed for the effect of treatment using a similar model that included the age of the individual calf at this stage as a covariate in the analysis.

Concentrate Intake. Daily concentrate intake was averaged over the 2 calves in a pair, and then weekly averages for the $4 \mathrm{wk}$ were calculated for each pair. These data were analyzed by a mixed model that included the fixed effects of social contact (I, V, T, $\mathrm{P}$, VP), sex combination (males, females, or mixed sexes), week $(1,2,3$, or 4$)$, the interaction between social contact and sex combination, and the interaction between social contact and week. Block was included as a random effect, and the covariance between repeated observations on the same pair over weeks was modeled as autoregressive of first order. In the initial analysis, 
contrasts were calculated between treatments $\mathrm{P}$ and VP to test for effect of age at pair housing. If no effect $(P>0.10)$ was found, the data for treatments $\mathrm{P}$ and VP were pooled (treatment AP) and, in a subsequent analysis, the 4 treatments (I, V, T, AP) were compared using contrasts.

Blood Samples. For all 3 variables (antibodies against BCV, PI-3, and BRSV), delta values were calculated by subtracting the value of the first blood sample (d 4) from the value of the second blood sample (d 49). These delta values for the 3 variables were analyzed as described above for undisturbed behavior, except that the level of total IgG on d 4 was included as a covariate.

Clinical Monitoring and Fecal Samples. To take into account the dependence between calves allocated to treatment as a pair, the pair was assigned a respiratory score of 1 if at least one calf had a respiratory score of 1 in a particular health check. Similarly, the pair was assigned a fecal score of 1 if at least one calf had a fecal score of 1 . For each of the 5 health checks, the effect of treatment on the number of pairs with a respiratory score of 1 was analyzed using the $\chi^{2}$ test or the Fisher Exact test if more appropriate. Similarly, for each health check, the effect of treatment on the number of pairs with a fecal score of 1 was analyzed using the $\chi^{2}$ test or the Fisher Exact test.

Fecal samples were analyzed for the presence or absence of the following infective agents; BCV, BRV, $E$. coli, Eimeria spp., and C. parvum. For each pathogen and calf, the number of health checks with a positive result was calculated. Subsequently, for each pathogen and pair, the number of health checks with at least one calf of the pair with a positive result was calculated. The variables were analyzed for treatment effects on the number of pairs testing positive in at least 1 of the 5 health checks using the $\chi^{2}$ test or the Fisher Exact test.

\section{RESULTS}

\section{Undisturbed Behavior}

The undisturbed behavior of the calves at $21 \mathrm{~d}$ of age is shown in Table 1. Calves spent approximately $5.5 \mathrm{~h}$ upright and 70 min feeding during the $24 \mathrm{~h}$ of observation, with no difference between treatments. Pair-housed calves (AP) sniffed or licked the fixtures of the pen less than calves in individual pens (I, V, and T). Pair-housed calves licked their own bodies less than calves in individual pens with only auditory or visual social contact, respectively (I and V), whereas calves in individual pens with opportunity for tactile social contact ( $\mathrm{T}$ ) were intermediate. Among calves on a treatment with opportunity for physical social contact, pair-housed calves (AP) sniffed and licked their peer more than individually housed $(\mathrm{T})$ calves.

\section{Behavioral Tests}

The behavior of the calves during the social test is shown in Table 2. Pair-housed calves (AP) had the shortest latency to sniff the stimulus calf, calves isolated with only auditory contact (I) had the longest latency to sniff, whereas individually housed calves with visual and tactile contact ( $\mathrm{V}$ and $\mathrm{T}$ ) were intermediate. Calves housed with opportunity for physical contact ( $\mathrm{T}$ and AP) sniffed the stimulus calf's muzzle more than I calves did, whereas $\mathrm{V}$ calves were intermediate. The duration of sniffing the stimulus calf's head or body and the duration of sniffing the environment did not differ between treatments. We detected no effect of treatment on the number of lines crossed or mean heart rate during the social test.

Treatment did not affect whether a calf was pushed into the arena or not (70 of 110 calves were pushed), but calves that had been pushed had a longer latency to sniff the stimulus calf (transformed means: $18.5 \pm$

Table 1. Behavior in the home environment (mean \pm SEM) of calves in individual pens with auditory contact (I), individual pens with auditory and visual contact $(\mathrm{V})$, individual pens with auditory, visual, and tactile contact $(\mathrm{T})$, or pair housing $(\mathrm{AP})^{1}$

\begin{tabular}{|c|c|c|c|c|c|c|}
\hline Behavior & \multicolumn{4}{|c|}{ Treatment } & $F$-value & $P$-value \\
\hline $\begin{array}{l}\text { Upright }(\mathrm{h} / 24 \mathrm{~h}) \\
\text { Feeding }^{3}(\min / 24 \mathrm{~h}) \\
\text { Sniffing/licking fixtures }(\min / 24 \mathrm{~h}) \\
\text { Licking own body }(\min / 24 \mathrm{~h}) \\
\text { Sniffing/licking peer }(\min / 24 \mathrm{~h})\end{array}$ & $\begin{aligned} 5.29 & \pm 0.23 \\
8.10 & \pm 0.55(66) \\
71.2^{\mathrm{a}} & \pm 6.7 \\
66.8^{\mathrm{ab}} & \pm 5.8\end{aligned}$ & $\begin{aligned} 5.31 & \pm 0.24 \\
8.57 & \pm 0.58 \\
78.0^{\mathrm{a}} & \pm 7.0 \\
64.7^{\mathrm{ab}} & \pm 6.1\end{aligned}$ & $\begin{aligned} 5.36 & \pm 0.22 \\
7.43 & \pm 0.55(55) \\
70.0^{\mathrm{a}} & \pm 6.6 \\
55.5^{\mathrm{bc}} & \pm 5.70 \\
8.0^{\mathrm{b}} & \pm 5.3\end{aligned}$ & $\begin{aligned} 5.85 & \pm 0.18 \\
8.85 & \pm 0.49(78) \\
52.8^{\mathrm{b}} & \pm 5.8 \\
47.7^{\mathrm{c}} & \pm 4.35 \\
56.7^{\mathrm{a}} & \pm 3.8\end{aligned}$ & $\begin{array}{r}F_{3,30}=1.81 \\
F_{3,30}=2.01 \\
F_{3,30}=5.52 \\
F_{3,30}=3.69 \\
F_{2,10}=55.66\end{array}$ & $\begin{array}{c}0.17 \\
0.13 \\
0.004 \\
0.02 \\
<0.001\end{array}$ \\
\hline
\end{tabular}

${ }^{\mathrm{a}-\mathrm{c}}$ Within rows, values with different letters are significantly different $(P<0.05)$.

${ }^{1}$ Observation of behaviors was conducted when the youngest calf in a block was $21 \mathrm{~d}$ old.

${ }^{2}$ Treatments $\mathrm{P}$ and VP pooled, where $\mathrm{P}=$ pair housing within $3 \mathrm{~d}$ of birth, and VP $=$ auditory and visual contact the first 2 wk followed by pair housing.

${ }^{3}$ Values were square root transformed before analysis. Back-transformed mean estimates are given in parentheses. 
Table 2. Behavior and heart rate during the social test and the novel environment test (mean \pm SEM) of calves in individual pens with auditory contact (I), individual pens with auditory and visual contact (V), individual pens with auditory, visual, and tactile contact (T), or pair housing $(\mathrm{AP})$

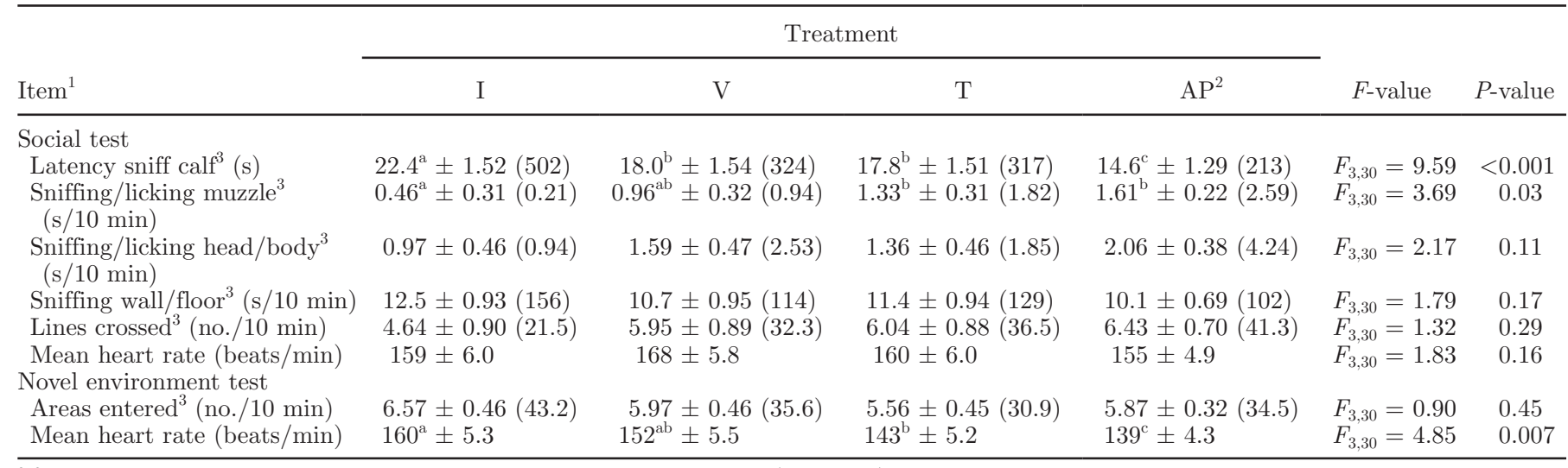

${ }^{{ }^{a} \mathrm{C}}$ Within rows, values with different letters are significantly different $(P<0.05)$.

${ }^{1}$ The social and novel environment tests were conducted when the youngest calf in a block was 44 and $46 \mathrm{~d}$ old, respectively.

${ }^{2}$ Treatments $\mathrm{P}$ and VP pooled, where $\mathrm{P}=$ pair housing within $3 \mathrm{~d}$ of birth, and $\mathrm{VP}=$ auditory and visual contact the first 2 wk followed by pair housing.

${ }^{3}$ Values were square root transformed before analysis. Back-transformed mean estimates are given in parentheses.

1.35 vs. $\left.15.7 \pm 1.35 ; F_{1.39}=5.37, P=0.03\right)$. Backtransformed mean latencies were 342 and $247 \mathrm{~s}$ for calves that were pushed and not pushed, respectively. Female calves crossed more lines than male calves (6.64 \pm 0.68 vs. $4.90 \pm 0.70 ; F_{1,60}=6.07 ; P=0.02$ ). Backtransformed means were 44 and 24 lines crossed for females and males, respectively.

The behavior of the calves during the novel environment test is also shown in Table 2. Pair-housed calves (AP) had a lower mean heart rate during the test than calves on the other treatments, whereas we observed no differences in the number of areas entered. More calves on treatments $\mathrm{T}, \mathrm{P}$, and VP vocalized during the test $(5 / 22,5 / 22,10 / 22,10 / 22$, and $14 / 22)$ for treatments I, $\mathrm{V}, \mathrm{T}, \mathrm{P}$, and VP; $\left.\chi^{2}(4)=11.14 ; P=0.03\right)$.

\section{Concentrate Intake}

We found no effect of treatment on concentrate intake, but intakes increased over weeks $(153 \pm 34.4,266$ $\pm 34.4,408 \pm 33.6,601 \pm 3.34 \mathrm{~g} / \mathrm{d}$, for wk $3,4,5$, and 6 respectively; $F_{3,143}=112.0, P<0.001$ ).

\section{BW Gain}

Treatment had no effect on ADG from birth to $4 \mathrm{wk}$ of age. Males gained more BW than females $(655 \pm 24$ vs. $584 \pm 23 \mathrm{~g} / \mathrm{d}$ for males and females, respectively; $\left.F_{1.47}=6.48, P=0.02\right)$. We found no effect of treatment on calves' BW at the end of the experimental period, but males had a higher BW than females $(82 \pm 1.0$ vs. $\left.79 \pm 0.9 \mathrm{~kg} ; F_{1,48}=6.87 ; P=0.01\right)$.

\section{Blood Samples}

The level of antibodies was expressed as the blocking percentage (range 0-100\%) such that high values indicate high levels of antibodies in the samples. Treatment had no effect on the amount of antibodies against BRSV or against PI-3 virus. Calves with visual contact had a greater change (delta value) in the amount of $\mathrm{BCV}$ antibodies between the first and second samplings [I: $27.30( \pm 7.46) \%, \mathrm{~V}: 43.38( \pm 7.68) \%, \mathrm{~T}: 29.67$ $( \pm 7.96) \%$, AP: $\left.26.64( \pm 6.90) \% ; F_{3,24}=3.25 ; P<0.05\right]$.

\section{Clinical Scoring and Fecal Samples}

No effect of treatment was found on fecal score at any single health check. Ninety-eight percent of the calves had a fecal score $>0$ on at least 1 of 5 health checks. No effect of treatment was found for respiratory scores at any of the health checks. Twenty percent of calves had a respiratory score $>0$ on at least 1 of 5 health checks.

No calves were tested positive for $E$. coli at any of the 5 health checks. No effects of treatment were found on the number of calves testing positive for any of the pathogens BCV, BRV, Eimeria spp. oocysts, or $C$. parvum oocysts at any single health check or on the number of calves testing positive for any of these pathogens at $\geq 1$ of the 5 health checks. Seven percent of the calves tested positive for BCV at $\geq 1$ of the 5 health checks, whereas $5 \%$ of the calves tested positive for $C$. parvum at $\geq 1$ of the 5 health checks. Fifty percent of the calves tested positive for BRV at $\geq 1$ of the 5 health checks, whereas $18 \%$ of the calves tested positive for Eimeria spp. at $\geq 1$ of the 5 health checks. 
No significant differences were found between treatment $\mathrm{P}$ and VP; that is, between calves pair-housed within $3 \mathrm{~d}$ of birth and at $2 \mathrm{wk}$ of age, for any of the measured variables.

\section{DISCUSSION}

Behavior was affected by the level of social contact. All calves housed individually were more reluctant than pair-housed calves to approach an unfamiliar calf, but isolated calves were most reluctant to approach and interact with the unfamiliar calf. The level of social contact had no effect on clinical scores, the presence of pathogens in feces, or the increase in antibodies against respiratory pathogens in serum, indicating no advantage on the general health of individual over pair housing, and no effect of avoiding tactile contact between individually housed calves.

In the social test, all individually housed calves had a longer latency to sniff an unfamiliar calf than did pair-housed calves, and the longest latency was that of isolated calves with only auditory contact. The treatments were defined to include an increasing level of social contact from only auditory contact over visual and tactile contact to full social contact in the pair pens. The study showed an effect of this increasing level of social contact on social responses during the social test; the latency to sniff the unfamiliar calf decreased, whereas the duration of sniffing the unfamiliar calf's muzzle increased with increasing level of social contact. In the social test, the stimulus calf was tethered to control its responses and to give the test calf the initiative in a standardized way. Jensen et al. (1997) and Duve and Jensen (2011) also found that individually housed calves were more reluctant to interact socially when they had to take the initiative during a test with a stimulus calf positioned in a specific place, whereas individually housed calves responded more aggressively to other calves' proximity and social investigation when these calves were loose (Veissier et al., 1994; Duve and Jensen, 2011; De Paula Vieira et al., 2012). In commercial settings, calves are typically weaned and grouped around the age of 6 to 8 wk. A high level of activity and agonistic behavior at grouping in previously individually housed calves is likely a disturbance in this situation, and it may interfere with the feeding transition from milk to solids, as De Paula Vieira et al. (2010) found that pair-housed calves consumed more concentrate after weaning and grouping than did calves that had previously been housed individually. Calves' social responses may become more flexible as they gain social experience later in life. In the present study, no effect of calf age at pair housing was seen, which sug- gests that the first 2 wk were not essential for calves' social responses at $6 \mathrm{wk}$ of age. Also, Duve and Jensen (2012) found little effect on social responses of housing calves together from birth compared with housing them together from $3 \mathrm{wk}$ of age when calves were tested at 5 to $7 \mathrm{wk}$ of age. On the other hand, when tested at 26 wk of age, calves that had been group-housed from $5 \mathrm{~d}$ to 12 wk performed more social behaviors than calves that had been individually housed in this period (Jensen et al., 1999), and a long-term effect of the social environment from birth to 3 mo of age has been found in calves reared by the dam (Wagner et al., 2012). Possible long-term effects of social contact to peers in preweaned calves deserve further investigation.

The individual housing used has, in some previous studies, allowed auditory and visual social contact (De Paula Vieira et al., 2010; Duve et al., 2012), whereas in others it has allowed auditory, visual, and tactile contact (Jensen et al., 1999; Duve and Jensen, 2011). In the present study, sniffing and licking interactions were observed among calves in individual pens with tactile contact; however, this was $<15 \%$ of what was observed among pair-housed calves, which is similar to the observations of Duve and Jensen (2011).

The present study showed that the behavioral responses of calves in individual pens with tactile contact, in some aspects but not all, were similar to those of pair-housed calves. Similarly to pair-housed calves, more calves with tactile contact vocalized when isolated in a novel environment. This might suggest that these calves were more affected by separation from their peer. On the other hand, these calves also had a lower heart rate during this test, which does not support an increased emotional response but rather suggests that calves housed with tactile contact and pair-housed calves were actively trying to reestablish contact with their peers. During the novel environment test, heart rate was not affected by areas entered (and thus not physical activity) and the higher heart rate in individually housed calves without physical contact is thus more likely to relate to a higher emotional response than to physical activity. Also similarly to pair-housed calves, individually housed calves with tactile contact sniffed the unfamiliar calf's muzzle more. However, all individually housed calves were more hesitant to approach an unfamiliar calf in the social test, suggesting that individually housed calves with tactile contact were more fearful of unfamiliar calves than were pair-housed calves. Thus, compared with isolation, individual housing with tactile contact reduced calves' fearfulness, but pair housing reduced fearfulness even more. This suggests that compared with isolation, tactile contact improves calf welfare, but pair housing improves it 
even more. This is of relevance to European legislation, which states that individually housed calves must be able to see and touch neighboring calves.

That calf welfare is improved by pair housing is supported by the calves' behavior in the home environment. The levels of licking own body and licking fixtures were lower in pair-housed calves compared with individually housed calves irrespective of type of individual housing. The licking of own fur and skin may relate to the inability to perform, and receive, social grooming. The licking of fixtures may be redirected social grooming or it may represent redirected exploratory behavior, as suggested by Wood-Gush and Vestergaard (1989).

The pens with closed sides (allowing only auditory contact) correspond to field situations in which calves are housed in closed pens or hutches, with no calves housed opposite and thus no visual contact with other calves. Closed sides of a pen block off visual contact to other calves as well as the view of the environment in general. Calves with only auditory contact in the home environment were the most fearful in novel social and environmental situations. The response of calves with visual contact lay between that of isolated calves and those with tactile contact; visual contact in addition to auditory contact appears to make little difference to calves' social responses.

We found no effect of treatment on concentrate intake or BW gain. Some previous studies have found higher intakes of solid feed in socially housed calves than in individually housed calves (Phillips, 2004; Hepola et al., 2006; De Paula Vieira et al., 2010). Calves on a low milk allowance, as in the present experiment, eat more concentrates than calves fed enhanced milk (see Khan et al., 2011), and it may be hypothesized that the effect of social housing is more pronounced when calves are fed more milk.

In the present study, concentrate intake was measured in a period of time defined by the age of the youngest calf in the block rather than the calf's own age. This may also have increased variance and may have made it more difficult to detect treatment differences.

Diarrhea and respiratory disease are the most important health problems in preweaned calves. The incidence and severity of disease is influenced by the animal itself; its environment and management; and the presence, level, and transmission of infectious agents. The ability of a young calf to cope with especially enteric pathogens relies on a few key factors: (1) immunoglobulin (mainly $\operatorname{IgG}$ ), absorbed from the colostrum during the first $24 \mathrm{~h}$ and re-secreted into the lumen; (2) local-acting immunoglobulin (IgA and IgG) supplied in subsequent milk feedings; (3) the ability of the calf to mount an effective immune response; and (4) the infection pressure (i.e., the risk of the calf being exposed to a pathogen). The health evaluation constituted clinical scoring and pathogen exposure assessed by laboratory tests for the most common calf pathogens. For respiratory viruses, paired serum samples were used as an indicator of infection. Bovine rotavirus and Eimeria spp. were the most common pathogens detected in the examined calves, with 50 and $18 \%$ of the calves being positive in $\geq 1$ sample, respectively, whereas BCV and C. parvum were detected less frequently. These findings are in accordance with findings in similar studies and reflect the age of the calves (Reynolds et al., 1986; de Verdier Klingenberg and Svensson, 1998). Only 2\% of the calves had a fecal score of zero at all 5 observations, which emphasizes that loose feces is a common feature in young calves, irrespective of housing conditions. The frequent detection of BRV and Eimeria spp. in the fecal samples indicates that these pathogens may have contributed to loose feces. However, no treatment effects on fecal scoring were detected and no differences in prevalence of the pathogens were seen between the treatment groups.

A significant increase in $\mathrm{BCV}$ antibodies in the groups with visual contact could indicate that these animals were more readily infected, but this finding had no effect on clinical respiratory disease in the present study. Overall, the present results are in concordance with previous studies that have shown that housing preweaned calves in larger groups was associated with higher incidences of respiratory disease, whereas no difference was detected between calves housed in small groups and those in individual pens (Svensson et al., 2003).

\section{CONCLUSIONS}

Increasing the level of social contact in the home environment made calves less fearful in novel social and environmental situations. Calves with only auditory contact were the most fearful, pair-housed calves were the least fearful, and individually housed calves with tactile contact were intermediate. Visual contact in addition to auditory contact had a minimal effect on calf behavior. Compared with isolation, tactile contact improves calf welfare but pair housing improves it even more. The type of housing had no effect on the presence of pathogens in feces or antibodies against pathogens in blood.

\section{ACKNOWLEDGMENTS}

The study was funded by the Danish Ministry of Food, Agriculture and Fisheries. The staff members at the cattle facility at Aarhus University (Foulum, Denmark) are gratefully acknowledged for care of experimental 
animals. We are grateful to John Misa Obidah for data collection and to Erik Luc Decker (both from Aarhus University) for assistance with data editing. Peter M. H. H. Heegaard, Solvej Østergaard Breum, Øystein Angen, Heidi Enemark Larsen, and Hue Thi Than (all National Veterinary Institute, Technical University of Denmark, Frederiksberg') are thanked for help with the laboratory tests.

\section{REFERENCES}

Bokkers, E. A. M., and P. Koene. 2001. Activity, oral behaviour and slaughter data as welfare indicators in veal calves: A comparison of three housing systems. Appl. Anim. Behav. Sci. 75:1-15.

de Graaf, F. K., F. B. Wientjes, and P. Klaasen-Boor. 1980. Production of K99 antigen by enterotoxigenic Escherichia coli strains of antigen groups O8, O9, O20, and O101 grown at different conditions. Infect. Immun. 27:216-221.

De Paula Vieira, A., A. M. de Passillé, and D. M. Weary. 2012. Effects of the early social environment on behavioral responses of dairy calves to novel events. J. Dairy Sci. 95:5149-5155.

De Paula Vieira, A., M. A. G. von Keyserlingk, and D. M. Weary. 2010. Effects of pair versus single housing on performance and behavior of dairy calves before and after weaning from milk. J. Dairy Sci. 93:3079-3085.

de Verdier Klingenberg, K., and C. Svensson. 1998. Group A rotavirus as a cause of neonatal calf enteritis in Sweden. Acta Vet. Scand. 39:195-199.

Duve, L. R., and M. B. Jensen. 2011. The level of social contact affects social behaviour in pre-weaned dairy calves. Appl. Anim. Behav. Sci. 135:34-43.

Duve, L. R., and M. B. Jensen. 2012. Social behavior of young dairy calves housed with limited or full social contact with a peer. J. Dairy Sci. 95:5936-5945.

Duve, L. R., D. M. Weary, U. Halekoh, and M. B. Jensen. 2012. The effects of social contact and milk allowance on responses to handling, play, and social behavior in young dairy calves. J. Dairy Sci. 95:6571-6581.

Grauballe, P. C., B. F. Vestergaard, A. Meyling, and J. Genner. 1981. Optimized enzyme-linked immunosorbent assay for detection of human and bovine rotavirus in stools: Comparison with electronmicroscopy, immunoelectro-osmophoresis, and fluorescent antibody techniques. J. Med. Virol. 7:29-40.

Gulliksen, S. M., K. I. Lie, T. Løkken, and O. Østerås. 2009. Calf mortality in Norwegian dairy herds. J. Dairy Sci. 92:2782-2795.
Henriksen, S. A., and K. Aagaard. 1976. A simple McMaster and flotation method. Nord. Vet. Med. 28:392-397.

Henriksen, S. A., and J. F. L. Pohlenz. 1981. Staining of cryptosporidia by a modified Ziehl-Neelsen technique. Acta Vet. Scand. $22: 594-596$

Hepola, H., L. Hänninen, P. Pursiainen, V. M. Tuure, L. Syrjälä-Qvist, M. Pyykkönen, and H. Saloniemi. 2006. Feed intake and oral behavior of dairy calves housed individually or in groups in warm or could buildings. Livest. Sci. 105:94-104.

Jensen, M. B., L. Mogensen, L. Munksgaard, and C. C. Krohn. 1999. Effects of housing in different social environments on open-field and social responses of female dairy calves. Acta Agric. Scand. A Anim. Sci. 49:113-120.

Jensen, M. B., K. S. Vestergaard, C. C. Krohn, and L. Munksgaard. 1997. Effect of single versus group housing and space allowance on responses of calves during open-field test. Appl. Anim. Behav. Sci. 54:109-121.

Khan, M. A., D. M. Weary, and M. A. G. von Keyserlingk. 2011. Invited review: Effects of milk ration on solid feed intake, weaning and performance in dairy heifers. J. Dairy Sci. 94:1071-1081.

Lidfors, L., and P. Jensen. 1988. Behaviour of free-ranging beef cows and calves. Appl. Anim. Behav. Sci. 20:237-247.

Martin, P., and P. Bateson. 2007. Measuring Behaviour: An Introductory Guide. Cambridge University Press, Cambridge, UK.

Phillips, C. J. C. 2004. The effects of forage provision and group size on the behavior of calves. J. Dairy Sci. 87:1380-1388.

Reynolds, D. J., J. H. Morgan, N. Chanter, P. W. Jones, J. C. Bridger, T. G. Debney, and K. J. Bunch. 1986. Microbiology of calf diarrhoea in southern Britain. Vet. Rec. 119:34-39.

Svensson, C., J. Hultgren, and P. A. Oltenacu. 2006. Morbidity in 3-7-month-old dairy calves in south-western Sweden, and risk factors for diarrhoea and respiratory disease. Prev. Vet. Med. 74:162-179.

Svensson, C., K. Lundborg, U. Emanuelson, and S. O. Olsson. 2003 Morbidity in Swedish dairy calves from birth to 90 days of age and individual calf-level risk factors for infectious diseases. Prev. Vet. Med. 58:179-197.

Veissier, I., V. Gesmier, P. Le Neindre, J. Y. Gautier, and G. Bertrand. 1994. The effects of rearing in individual crates on subsequent social behavior of veal calves. Appl. Anim. Behav. Sci. 41:199-210

Wagner, K., K. Barth, R. Palme, A. Futschik, and S. Waiblinger. 2012 Integration into the dairy cow herd: Long-term effects of mother contact during the first twelve weeks of life. Appl. Anim. Behav. Sci. 141:117-129.

Wood-Gush, D. G. M., and K. Vestergaard. 1989. Exploratory behavior and welfare of intensively kept animals. J. Agric. Ethics $2: 161-169$ 